\title{
Phenomenological Contributions to Transcultural Psychiatry Through the Care of a Brazilian Indigenous Person
}

\section{W.I. Miyamoto ${ }^{1}$, E.F.C. Pellegrino²}

1'Instituto de Psiquiatria do Hospital das Clínicas da Faculdade de Medicina da Universidade de São Paulo, São Paulo, Brazil.

2UFPA Federal University of Pará, Medical School, Altamira, Brazil.

(wi.miyamoto@gmail.com)

\section{Introduction}

Contemporary psychiatry bases its many diagnoses on a determined cluster of given signs and symptoms; by considering itself "atheoretical", diagnostic classification systems such as the DSM-5 put aside the relevance that should be given to the fact that the diagnostic act itself is culturally determined, when such fact should always be taken into consideration, specially when dealing with a person whose cultural roots are different from our own. By giving a psychiatric diagnoses to an individual through a given sum of signs and symptoms, the social and cultural context in which the person is embedded is relegated to a secondary status.

"The phenomenological perspective (...) advocates that the context of the clinical encounter should be one of co-presence (and not of dominance) with the aim of understanding (and not labelling), i.e., negotiating inter-subjective constructs and looking for meaningfulness through the bridging of two different horizons of meanings" (Stanghellini, 2007). Phenomenological psychopathology, by attempting to view the person not through his or her behavioral manifestations inside his or her own culture, but through the lived aspect of these behaviors, that is, through the meanings of the behaviors as a part of a whole which is the individual, is able to transcend the cultural differences that, in theory, would demarcate a separation between the interviewer and the interviewee, without putting those differences aside.

In this poster, we attempt to analyze and describe the phenomenostructural impressions given by the clinical encounter with a Brazilian indigenous person with psychosomatic symptoms, inside his cultural context, and, with such an analysis, make a contribution to the field of transcultural psychiatry.

\section{Case Description}

The patient was a 39-year-old indigenous person living in a village on the banks of the Iriri river, in the city of Altamira, Brazil. He had many unspecific bodily symptoms, such as nauseas, abdominal pain, dizziness, headaches, and had already been submitted to multiple kinds of treatments (from psychological to surgical ones); he said that he would go occasionally to the city of Altamira to go through medical examinations, and that the doctors would always tell him to take blood tests and imaging exams. He would constantly demand, during the interview, for imaging exams, such as an MRI, in order to be "seen from the inside", and in this way be treated correctly. We tried to talk to the patient about other subjects, such as his life history; however, he would always go back to his bodily complaints.

During the interview, the patient would receive multiple calls from family, and from the FUNAI - Fundação Nacional do Índio (Indigenous National Foundation) team, to ask him how he was, and if he had gone to the medical appointment. He said he had noticed, ever since he had gone ill, that people around him would be constantly worried with him, which he sees as a good thing.
By the end of the interview, we told the patient we didn't judge as necessary to ask for more blood tests or imaging exams; he got very irritated with us, and said we were denying him the "white man" exams that would show what illness he has got.

\section{Phenomenological analysis}

It became clear to us, during the interviews we had with the patient, that he would constantly put the authors in a position of supremacy, with overpowering abilities to find out which illnesses he had, and to cure him from his symptoms.

Messas et al (2018) consider relational hypo-sufficiency to be the main characteristic of hysterical interpersonality, in which the I of the hysterical person subjugates itself to the other. Through the lens of embodiment, this hypo-sufficiency is shown as a body excessively placed as a function of the eyes of the other. The embodiment of the hysterical person is traversed more by passive suffering than by active elaboration (Messas et al, 2018). Such fact becomes clear to us, when the patient, seeing both the authors as medical doctors, put them in a position as the ones who had the power to diagnose and treat his medical diseases.

Such subjugation can and must be also seen within the cultural context in which the patient is placed. The patient not only subjugates himself to the eyes of the interviewers, but he also subjugates his culture to the culture of "white men". This subjugation appears constantly in the intersubjective relation during the consultations, as an expression of the dimension of the lived. It is important, therefore, to indicate the complex interconnections between the subjective symptoms and the social pathology in which they take place, since, historically, the "white men" culture has indeed dominated consistently the indigenous culture. This raises the important issue that an ethical-political commitment with the social particularities and local cultures must also be urgently made.

\section{Conclusions}

Phenomenology can and should found an universal psychiatry, in that, by its own method, it forbids itself from separating subject from object, the individual from the world, and, more precisely, from the human world (Tatossian, 2001). It becomes clear, therefore, that, when facing a patient whose cultural backgrounds are different from our own, we should not merely make a list of signs, symptoms and behaviors that the patient has, but instead discover the meanings of the behaviors expressed. Through this brief case description and phenomenological analysis, we hope to have contributed to the field of transcultural psychiatry, both by shedding some light over it with the phenomenological method, as well as by raising some questions regarding the cultural differences between different Brazilian populations, and how that should be taken into consideration when facing a patient.

\section{References}

1. Stanghellini G: The Grammar of the Psychiatric Interview. Psychopathology 2007; 40:69-74.

2. Tatossian A: Culturas e Psiquiatria. Rev. Latinoam. Psicop. Fund. IV, 3, 131-136.

3. Tatossian A: Cultura e Psicopatologia: um ponto de vista fenomenológico. Rev. Latinoam. Psicop. Fund. IV, 3, 137-144.

4. Tatossian A: Sintoma e Cultura: algumas observações. Rev. Latinoam. Psicop. Fund. IV, 3, 145-149.

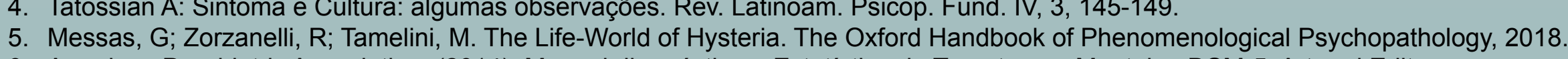

